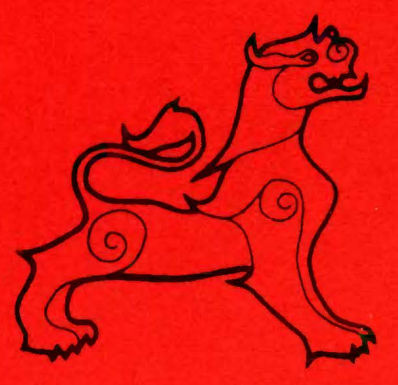

The Afghanistan Council

of

\title{
THE ASIA SOCIETY
}

\section{0}

OCCASIONAL PAPER NO. 
A CULTURAL ANALYSIS OF AFGHAN

FOLKTALE THEMES

CAROI ANN SIGEL

October, 1974

Carol Ann Sigel is a graduate of Goucher College with a B.A. degree in Political science she later changed to the field of Education for her Masters degree at American University in Beirut, Lebanon -- primarily because of an interest in children's stories. She grew up in a Navy family and has lived in many parts of the world and developed an interest in the folktales of each area. Three years residence in Afghanistan gave her the opportunity to study the folktales of that country, which she used as the basis for her Master's thesis.

The Occasional Papers are part of a subscription series distributed by the Afghanistan Council of The Asia Society. To qualify for publication, papers must represent solid original research related to the humanities and the social sciences. Translations of such materials from Dari or Pashto will also be considered. Please address all inquiries to the Council at 112 East 64 th street, New York, N.Y. 10021 .

Views expressed in the Afghanistan Council publications reflect those of the authors and not the Afghanistan Council or The Asia Society.

Subscription information: for Newsletters, Occasional \& Special Papers.

$\begin{array}{lcc} & \text { U.S. \& Canada } & \text { Overseas } \\ \text { Annual rates } & \$ 5.00 & \$ 6.50 \\ \text { Per issue } & \$ 1.25 & \$ 1.75\end{array}$

A list of past publications is available upon request. 
The following Occasional Paper should be considered in its true context as just one chapter of a thesis consisting of five chapters.

The purpose of the thesis was to collect for children a number of folktales from the oral literature in the developing country of Afghanistan. More specifically the research aims to perpetuate a part of this heritage and to encourage the idea of a special literature for young people by the analysis of the cultural content of the stories and by recommendations as to their creative function in the curriculum. It seeks to suggest that the stories can perform a three-fold function when properly presented in written form.

First, they can be a means of promoting the personal and social growth of the children. Second, the tales help to preserve important values in the culture while at the same time they may indicate some of the traditional values which should perhaps be changed to meet the needs of an increasingly modern society. Third, they can add variety to a rather formal curriculum, thereby attempting to meet some of the individual, social and educational problems of children which are posed in the research.

The methodology of the research included:- First, the collection of a large number of folktales from the oral tradition by tape recorder. These were gathered from many sources -- children, teachers, parents and grandparents. They were taped in Farsi, Pushtu and a few in English. All were later translated and taped in English. Because the population in the Helmand Valley project, where the tales were gathered, included many from other provinces the stories are representative of many other sections of Afghanistan.

Second, information for discussion of the cultural background and traditions was drawn from many Afghan leaders and citizens as well as the author's own experience while living in the country for over three years.

Third, library research to investigate certain sociological principles of folktales as well as to pursue in depth elements of Afghan life and culture as they relate to the stories.

Fourth, primarily in the chapter reproduced in this paper, an analysis of the material vis-a-vis some of the cultural and universal values expressed. Recommendations were also included for suggested ways to use the stories in the school curriculum to help develop creativity in the children. 


\section{A CULTURAL ANALYSIS OF AFGHAN}

FOLKTALE THEMES

In folktale themes one finds the expression of both universal and cultural values. The universal themes seem to reflect the aspirations, dreams and standards which are a part of fundamental human experience through successive generations. Time and again one finds good triumph over evil, poverty become wealth, failure turn success or love that conquers all obstacles. Doubtless, some of the themes of the stories indicate a serious purpose. Tales were told, for instance, to explain the phenomenon of nature, to give warning against breaking the laws of god or nature, or were related in an attempt to make the listeners kind, courageous or unselfish. But, perhaps the true delight of the themes comes from their expression of a free and joyous play of fancy and the manifestation of the human heart's love for truth and beauty. For through the fantasy a fairytale world is created, a world of happy-ever-afterings, which frees an individual at least for a moment from the problems and tedium of daily life.

However, within folktales, one also finds concepts which indicate certain cultural attitudes and values of a particular group of people. These might stem from social custom, religious tradition, historical events or a combination of such woven into a pattern which is unique to a community. Take, for example, the tale of Cinderella. Told more than a thousand years ago in Iceland, it is said to have more than three hundred variants. Stories like it have been told in England (Tattercoats), Ireland (Fair, Brown and Trembling), Germany (Ashenputtel) or among the American Indians (Little Burnt Face). Although the germ of the story is the same, the details have the characteristics of the land of its origin. In this way many of the most important values in a society are incorporated within a tale and the 
heritage is preserved. 1

Universal and cultural themes are by no means mutually exclusive. There occurs in fact much over-lapping both within and between cultures. Yet, as this paper will endeavor to indicate, the two types of themes can to some extent be separated, the emphasis here being on the cultural elements in Afghan folktale themes.

As one studies Afghanistan, past and present, diversity seems to characterize the land and its population. Geographically, there is great contrast as the terrain ranges from the high barren mountains, through small, but fertile valleys, to the arid deserts. Historically, the country has been a crossroads between East and West for trade, migration and invasion. The groups either pausing or settling in this territory were, therefore, of different ethnic strains and brought with them their religions and traditions. Although the difficult nature of the country inhibited communication among those who chose to remain thereby creating a number of fairly isolated cultural and tribal groups, the mountain corridors provided routes through which the others could pass. Today Afghanistan still bears the imprint of this in the variety of peoples and languages encompassed within her borders.

Inspite of the apparent divergencies of race and tradition, there does exist a cultural bond which has created a certain unity in this land. Perhaps two factors have contributed to the sense of solidarity in Afghan society. The first is tribalism with its strong tribal code; the second the faith of Islam. A third element stemming in large part from the aforementioned is the social structure which characterizes family and group relationships. The Pushtoons, the most significant tribal group in Afghanistan have established

I Lillian Hollowell (ed.), A Book of Children's Literature (3rd ed.), New York: Holt, Rinehart \& Winston, Inc., 1966: / p.33 
in their unwritten code, The Pustunwali, some important traditions. Essentially, the code defines a way of life, the adherence to which both protects the tribal members and maintains order within the community. According to Fletcher, principal tenets include: the hospitality which a host is honor bound to offer freely to his guests; the protection of one in search of refuge and the loyal assistance of the mediator until a settlement has been achieved; the idea of promises when made must be kept at all costs; the principal of honor and courage in battle and self-respect in family and group life; and finally the concept of $\underline{\text { righteousness derived in part from Islamic teachings which stresses sincerity }}$ and truthfulness regardless of the consequences. These values, deep rooted in the Afghan heritage, are a powerful force not only among the Pushtoons, but also among those groups outside the direct provisions of the code. ${ }^{2}$ Another great influence in Afghan life has been the Moslem religion. Since the first Islamic conquests of the country, the religion with its many implications has been both the faith and guide for secular organization. Thus, Islamic law is significant in religious belief and worship, personal ethical behavior, social relationships, the formation of law and government, business transactions and the like. In other words it is defined as a total integration of religious values and daily life. Most Afghans are intensely religious people and neither wealth nor power command respect like that held for a man of faith. 3

Belief is characterized by two trends of thought although seemingly contradictory do in many instances function as a whole. First, there are the concepts of submission to the authority of religious principles, calm endurance of adversity and acceptance of those aspects of life thought determined by fate. Further devotion to the Five Pillars of the religion which are the profession

2Arnold Fletcher, Highway of Conquest, Ithaca, Cornell University Press, 1965, pp 24-25.

3Donald Wilber, (ed.) Afghanistan: its People, its Society, its Culture, New Haven, Human Relations Area Files, 1962, pp 113-114. 
of faith, prayer, fasting, almsgiving and pilgrimage are considered to be essential. Secondly, tribalism and to some extent Islam glorify the man of action which in Afghan tradition brings vigor to the idea of a good life. Courage, candor and decision are respected while greed, bad-temper and recklessness are despised. In addition, a good reputation is an essential attribute. Far more than material gains does it stir a man to action. Fatalism thus in religion coexists with the rigorous traditions of tribalism. 4 In the folktales, one finds examples of both strands of thought which sometimes complement and sometimes supersede one another and which are frequently colored by superstitions derived from misinterpretation. The third element, the social structure, has been determined in large part by Islamic and tribal values, Essentially, Afghan society is organized in concentric rings extending out from the individual to the family, the tribe and the major ethnic group of which he is a member. These successive social layers direct, from a person's earliest years, his behavior and attitudes. To these groups he gives loyalty, co-operation, and service; from them he derives protection, a livelihood and a sense of "belonging." Thus, on one hand the individual is confined by bonds forged by custom. on the other hand he is freed from the terrors of loneliness. 5

Traditional society in Afghanistan indicates two main trends. One is rural in outlook with roots in the land. The other consists of the numerous tribes, free wanderers of the mountains and deserts. Both are characterized by a high degree of self-sufficiency, a strict adherence to tradition and an orderly, co-operative pattern of existence. Further, both tend to be individualistic rather than collective, yet the individualism is expressed

\footnotetext{
${ }^{4}$ Ibid. , p. 127

I Ibid., p. 121
} 
in the family or group, not in self-centered gain. 6 Perhaps, the greatest difference between tribal and rural communities is that the former tends to be more democratic in nature, the latter more paternalistic. For example, the decisions reached in a tribal group are usually made by a council of male members, while those of a farming community are frequently dictated by the local landlord. Or as in the case of the position of women, those of nomadic affiliation share in a greater part of the work and go unveiled while those living in villages are kept in almost strict seclusion.

In the final analysis, however, although there exists a wide diffusion of groups in Afghanistan, in reality the social and religious boundaries of each group are at once quite similar and narrow. An individual is expected to adhere to the established patterns and strong social pressure tends to maintain these principles in fact. In turn, the folktales have incorporated the ideas and perpetuated them.

In the following discussion, therefore, an attempt will be made to delineate some of the various themes and values of cultural significance which are expressed in the folktales. Themes can be roughly defined as recurring ideas forming a framework for each of the stories. They are in fact the motifs around which the stories are built. Many of the tales incorporate similar themes. For example, the idea of reward for goodness and punishment for wickedness appears in different contexts, yet the essential elements remain the same. In many cases the theme may emphasis particular values such as honor, promise or loyalty which are of importance to a people. These values give a special meaning to the stories which perhaps accounts in large measure for both their existence and their enduring quality. Most frequently the value and the theme are subtlely interwoven. If one takes, for instance, the theme of social 
mobility in a rigidly organized society, the values which underlie that theme maybe those of intelligence, industry or perseverance.

Thus, in order to better understand the cultural elements in the folktales, the author will try to identify major themes and their supporting values. Examples will be drawn from the stories that seem to best exemplify the topic under discussion.

\section{The Themes:}

The concept of fate or predestination derived in large part from Islamic teaching is important in the lives and thought of the Afghan people. In essence, it dictates that a superhuman power regulates the life of man and decides his destiny. As life is unpredictable, one must stoically accept both the good and the bad. Fate cannot be changed, for God puts a limit on each individual's life which he can neither go beyond or alter. When one recognizes fate as an integral part of a situation, one is obedient to it. But, if a goal is pursued regardless of cause or if destiny is deliberately denied, the individual is punished.

One example of fate can be seen in the story "The Princess and the Slave". The theme here revolves around the only daughter of a king who fortunetellers predict will marry one of the palace slaves. Both father and daughter object strongly to the liaison and set two impossible tasks for the young man to accomplish. But, the slave meets the challenges, thus, the princess accepts him in marriage. Destiny was, therefore, fulfilled regardless of the obstacles set by man.

Another instance of fate can be found in "The Wicked Daughter." A king with eight sons wishes for a daughter despite the warnings of his ministers. When the child is born and grows, evil things begin to occur. Her father blinded by love refuses to believe his daughter is the cause of a situation 
which finally brings death and destruction to the kingdom. The horror of the story is probably exaggerated to emphasize the major point and the listeners aware of this look for deeper meaning. The connotation would seem to be a religious one in that God puts limits on an individual's life. If he wishes for more than his share, he must accept the consequences Retribution, therefore, is inevitable though it might occur in varying degrees of severity. Religious attitudes stress the need for obedience to divine laws and order. In Afghanistan, Islam has created a nation of faithful to the beliefs and social practices of the religion. Even in pre-Islamic days, man tended to be respectful of the power of the supernatural whatever his order of belief. Works of art and literature still testify to the rich variety of faiths which were once found in this land. In the story "Baba Kharkash and the Magic Duck" a poor woodcutter follows carefulily the directions of a saint who appears to him in a dream. Although the woodcutter achieves at first great wealth, he loses all again because of his disobedience.

In addition, the heroes in the stories are usually obedient to sages and wise magicians perhaps an extension of the power of good. But, the magicians who represent evil or dishonesty are challenged by the heroes and most often destroyed. An example of the first can be seen in "The Princess and the Slave" where success comes in compliance with a supernatural power, However, in "The Magic Flower" the evil of the magician is extinguished after a long and bitter battle。

Many ancient and religious philosophies tend to stress the non-material aspects of existence. This would seem to stem from the concept that the good life on earth leads to rewards in the life hereafter where ultimate justice and happiness is achieved. Conversely, pubishment perhaps in this world and most probably in the next is the divine penance visited on those who pursue evil ways. In such philosophies material possessions or position are of secondary importance. The emphasis is rather on aspects of character which reflect goodness in a broad 
human sense. Included here might be the attitudes of kindness, generosity or friendship regardless of one's position or resources. Such values cannot be classified in the same way as material possessions and they are in addition an asset not only to a few, but to many.

Take for example the story of "The Old Woman." In this tale an old woman wishes to be freed from the toil and poverty that characterizes her life. A wiseman performs a series of transformations each one of which fails because of the excessive greed of the woman. Thus, one sees the contrast between the material and non-material outlook. On one hand there is the sage who in his broad human outlook can give without taking for himself; on the other there is the old woman who is overcome by the need to acquire personal earthly possessions. In many of the other stories such as "Baba Kharkash and the Egg of Happiness," "The Yellow Cow" or "The Princess and the Slave" the virtues of promise, honesty and good deeds are shown to be valued far more than material worth.

As has been previously mentioned tribal values play a significant role in the stories. Included here are the concepts of promise, cooperation, self determination and pride as well as that of loyalty coupled with other values. First, there is the idea that promises must be honored whether the individual is rich or poor, weak or strong. The underlying idea of this principle is one of self and communal preservation, protection and honor. The results are generally reflected in a stronger, more unified group which is better able to cope with the rugged challenges of reality.

An instance of this can be seen in "The Magic Flower." In this story a merchant travelling abroad seeks to fulfill the requests of his three daughters. The jewels and fine fabrics desired by the eldest two are easily obtained, but the special flower requested by the youngest daughter poses a difficult problem. Finally, the merchant is approached by a magician who gives him the flower in exchange for his daughter's hand in marriage. But the merchant does not take 
the magician's request seriously hence much is fought for as a result with a broken promise forming the basis for the tale. Another example of a more positive nature can be noted in "The Old Woman." Here the prince despite his dismay at being deceived keeps his word by giving to the old woman the palaces and property which he had promised her while under the impression that she was a lovely young princess.

Second, cooperation and interdependence are essential to both the effectiveness of a highly organized group and to the sense of well being for the individual. Therefore, each member of the community contributes his best efforts toward a common goal, the result of which enhances group power and productivity. Similarly, the individual realizes a sense of security in knowing the role which he is expected to play however great or small it might be.

In "The Palace of Diamonds" one finds repeated instances of cooperation. Here a prince although newly married hears the news of the king of China's beautiful daughter and sets out to win her hand. After many days, the princess becomes concerned about her husband's welfare and starts out to find him. By means of the kind and persistent help of a sage, the princess not only finds the prince, but also rescues him from the dungeon in which he has been left to perish. Thus, through cooperation the goal is achieved. Third, although interaction is stressed in tribal society, credence is also given to self-determination and pride. Both on the individual and social level the threat of domination is feared and hated. Great emphasis is placed on these values which beginning with the individual extend outward to the family and the group. Historically, there have been numerous examples in which the Afghans have viewed with hostility any type of interference with their traditions and especially in the nineteenth century have fought with 
bitter determination to maintain their independence. In addition, the tribal decision-making councils reflect the concept that each member has a right to share in the creation of group policy. It is interesting to note that religion here becomes a foreign element not evolving from the early historical processes. For in Islam, obedience is more valued than self-motivation. Thus, it is culturally stressed that strong self-determination and pride in achievement will aid in success. Sometimes forces from the unknown will be significant as an additional impetus to the events in progress. For example, in the story of "The Orphan" a poor young boy falls in love with the daughter of a king. Despite his lowly position, he is determined to win her for his wife. The plot revolves around his efforts aided by the intelligent use of the forces at his command to gain the hand of the princess. With perseverance and pridehe overcomes the challenges to be rewarded in the end by the realization of his goal. Although this story involves an individual, the same values are prevelent in the larger social organization.

Fourth, the concept of loyalty is important in the value system. Loyalty cannot be seen, however, in the context of blind and complete obedience. Rather it must be won through respect, a factor which gives greater meaning to the idea. Therefore, a leader to achieve the loyalty of his followers must by his attitudes and actions win their respect.

Similarly, the members of a group must be taught to value their heritage in order to insure their loyalty.

In the tale "Baba Bilisti" the concept of loyalty is expressed through love. In the story a princess marries a dwarf only to discover that he is the enchanted son of a fairy king. In trying to aid the situation, she throws the prince's magic skin into the fire which in reality threatens to destroy him. However, with love and loyalty the princess pursues her goal to win back her husband regardless of the magic obstacles and the prince is not 
daunted in his attempts by the challenges which lay in his path. Therefore, the mutual respect and understanding established early in the story are not shaken by adverse circumstances, but rather proved to be the key to a successful conclusion.

As with religious and tribal values, social relationships being a significant factor in Afghan society are reflected in the folktale themes. One discovers different aspects of individual, family and group behavior and attitudes in the context of the stories. Within the family structure individuals have certain roles and expectations which they are required to fulfill. An example of this can be noted in the views expressed towards the position of women. Here two trends are evident which to a large extent indicate a difference between tribal and religious values. The first has cultural antecedents in pre-Islamic society when women had more responsibility and were permitted greater social participation than under Moslem law. These attitudes were incorporated into the tribal system where even today women are important members of the community sharing not only in productive labor, but in responsibility for maintaining social and cultural traditions. An example of this can be seen in the story "The Magic Ring" in which the woman is the actual hero of the tale. With intelligence and persistence she removes the magic spell that had been cast on a handsome young prince and wins his love in the happy conclusion. The second trend is part of the tradition stemming from Islamic precedent in which a woman assumes a subordinate position in society. Having few actual rights, a woman owes almost complete obedience to her family and husband and must accept without question their decisions. It is not unusual, therefore, for a wife to be subjected to some sort of physical punishment for fractious behavior. A woman in such a relationship becomes more of an object than a helpful, constructive partner. An instance of this can be 
noted in "The Palace of Diamonds." In this story the prince severely disciplines his wife, in revenge for the time when she as his tutor had punished him. Again in "The Lady Bug and the Mouse" one finds a similar theme. Here a lady bug starts out to find a husband, the criterion for which is the instrument he would use to punish her when things are amiss. It seems a foregone conclusion that men as prime authorities in the household can use any means they wish to enforce their rule.

In addition to the patterns established in family relationships, there are also certain values which each member of the group is expected to uphold. Perhaps one of the outstanding traditions is that of family honor. From the very earliest years a child is brought up with the idea of the need to protect the good name and reputation of his family. This is significant not only in maintaining family ties, but also in reinforcing social relationships. Among the lower class commitment to the principle is especially strong because with limited social mobility, the environment offers few other supports to self dignity and pride. Therefore, family honor as with other values in the culture tend to be more inflexibly adhered to in lower class groups since it gives a meaning to life which cannot be achieved through wealth or position.

In the story "The Quince Fruit" a merchant travels far to bring back the special fruit which will cure his sick wife. One day the husband notices that a servant has one of the special quinces in his possession. The merchant does not believe the true explanation in which his son is said to have stolen the fruit and given it to the servant. Rather he holds to the second story that indicated his wife's unfaithfulness. When he returns to find a quince is really missing he kills his wife in fury. Here family honor is stressed to such a degree, that one becomes blinded to the true facts. As patterns have been established in family relationships, similarly a hierarchy has developed in social class groupings. Although wealth and 
position are not without their influence, ancestry determines in large part one's social standing. For example, it has been traditionally the Pushtoons, the largest and most forceful group in the country who have been the ruling class in Afghanistan. Their customs, political organization and policies have given these people an almost incontestable position in society. Even the king and his closest advisors were members of one of the largest tribes in the land, the Mohammedzais.

The pre-eminence of a particular group was reinforced to some extent by Islamic principles as the religious laws and customs crystallized heretofore less formal patterns of relationship. Thus, certain factors vis-a-vis an individual's position in a particular social class are apparent. For instance, social mobility in such a system is limited. Marriage between individuals of different classes is viewed unfavorably. An example of this can be noted in "The Palace of Diamonds" in which the king objects to his son's marriage with his tutor despite her background and upbringing as the daughter of a Mullah. This lack of upward mobility effects especially the lower classes for without economic resources such things as education or wealth which could lead to higher social status are not attainable. However, if an individual does succeed inspite of the obstacles he must have the proper social recognition to confirm his achievement. Therefore, if a man wins position through approved channels it is acceptable to the society in general. Similarly, when he does not have the proper social backing his higher status is not recognized. Thus, these traditions have created a fairly rigid class structure.

It is interesting to note that the heroes and heroines in fairy tales frequently violate the patterns established in the social hierarchy. Further, they are not punished for their presumptuous behavior, but rather in most cases succeed. This would seem to be an exaggeration of the desire and need to attain a better position in life. 
For example, in the tale "Baba Kharkash and the Egg of Happiness" a poor woodcutter with the aid of an unknown magical helper becomes a wealthy man. Fearing people will think that his fortune was obtained by unscrupulous means, he sends his daughter to be a lady-in-waiting at the king's court. The rationale is that his wealth would not be an object of suspicion if his daughter were receiving favors from the royal family. It happens one day that a diamond necklace belonging to the princess vanishes. The daughter who was responsible for the jewelry is accused of theft and similarly the wealth of the woodcutter comes under suspicion. However, when the truth is revealed, the family's possessions are returned three-fold by the king. Here one can see that the woodcutter is conscious of social class traditions and attempts to conduct himself accordingly as he realizes wealth alone is not sufficient.

In folktales there are also examples of individual intelligence and honesty leading to a higher social position. Perhaps, it is more the reality of fairytale life than of everyday existence, yet it seems that both are values within the culture as they appear frequently within the stories.

First, the type of intelligence described is more practical than academic in nature as could be expected in a land where life is difficult and survival often a challenge. Therefore, intelligence is not only an asset, but it is also essential for protection and safety. An example of this can be seen in the "Donkey and the Wolf" which is the tale of a donkey who cleverly outwits a wolf and thereby maintains his own well being and security. Further, intelligence is not the prerogative of any particular group, but rather can be an attribute of any individual. With the proper use of wisdom, it is not impossible for a humble man to achieve such things as social status or wealth. As in the "Mountain of Gems" a poor young man goes to seek his fortune. While in the employment of a well to do merchant, the boy learns the secret of the great treasure which had made the merchant rich. Like 
many before him, the boy nearly looses his life because of the cunning of his master. But, by means of the intelligent use of his resources, the boy employs the merchant's own plans against him, thereby winning wealth and position.

As with intelligence individual honesty frequently leads to rewards. It has meaning both inside and outside the family framework as do the values of hospitality or promise. Therefore, if two people have the same opportunities, success is on the side of the individual who is honest. Moreover, humbleness and honesty can lead to love from others as well as increased standing.

In "The Yellow Cow" whose theme is similar to that of "Cinderella", one finds a stepdaughter who is subjected to much hard work and punishment by her stepmother. However, with the aid of her magical helpers and by means of her own exemplary behavior, she wins both love and position. This is perhaps an idealized interpretation of a cultural value, nevertheless the point quite clearly states that honesty is a virtue which is both admired and rewarded.

The preceding discussion should, therefore, indicate that, as reflected in folktale themes, the basis of social class in Afghanistan is invariably a combination of factors. Membership in a favored ethnic group or religious sect does not by itself give an individual or a family social distinction. Wealth, if it is believed to be ill-gotten, may earn a man disrespect rather than prestige and wealth unaccompanied by intelligence or social graces, may be an object of contempt. The intangible virtues of renowned ancestry, demonstrated capability, a reputation for piety, valor, hospitality or character are values which carry high prestige among the Afghans. If there is a combination of these with wealth or power, the basic factors are reinforced and position becomes firmly established. 
Finally, in the discussion of cultural themes the historical trends found in such stories as "Fata and His Love" and "Sultan Mahmoud" should be mentioned. The former tells of the son of a powerful king who desires a kingdom of his own. Fata marches with his fiancé and warriors to India, in order to free himself from his father's influence. But, there in defeat he loses all. This story reveals the disunity which sometimes occurs among proud members of various tribes. In addition, the charmer in the tale is symbolically sent to weaken the Afghan warrior's spirit. Throughout history there have been examples such as this used to reinforce the principle of the disgrace of dishonorable conduct in battle. Perhaps the shame visited on Fata and his men can be interpreted as punishment for their fractious behavior.

The second story is taken from those told about the famous king, sultan Mahmoud of Ghazni. Here is attributed to him some of the qualities thought to be outstanding in a monarch. Included are such things as justice, concern for the people's welfare, understanding and hard work. In addition there is reflected a paternalistic attitude as he cares for his subjects, protecting them from evil. This seems to create a picture of stability which characterized the reign of Sultan Mahmoud.

Both these stories are probably part of a larger work describing in greater detail the historical pageantry of the country. However, from this small sample one can detect the values, real and imagined, which form a somewhat fairy tale-like picture of the past.

Although the concept of magic suggests a theme of a more universal nature it does on occasion have additional significance in the cultural context. According to the particular society magic has served in great part as an explanation of cause and effect in nature as well as a means of extending man's limited world through fantasy. 
The origins of magical power have differed in various cultures. One traditional source has been attributed to the forces of celestial bodies especially those of the sun and moon. In "The Princess and the Slave" one finds that the sun is the force which enables a poor slave to accomplish his objectives. The secrets entrusted to him by this power bring him not only wealth and grace, but also the hand of a princess in marriage. In other tales such as "Baba Kharkash and the Magic Duck" the magic seems to have more of a religious significance. The more sophisticated explanation of supernatural law is probably the result of the Islamic influence in the country. Still another source of magic is that attributed to human beings. In some cases a sage or wiseman uses his resources to help an individual reach his goal or to assist him in times of necessity. An example can be found in the story of "The old Woman" in which a sage attempts to contribute to the happiness of a woman by granting her wishes in a series of magical enchantments. However, the converse may be true as in the tale of "The Magic Flower" where the magician works not for good purposes, but rather seeks to create chaos and destruction with his supernatural powers.

The magic of the fairy tales also gives scope to the imagination of a people whose world is relatively limited. It provides a release from the tedium of routine life as its power works to permit men to achieve miracles. Magic is, in addition, a factor in a traditional society where individuals do not have the tools to cope with nature without the help of the supernatural. As in the tale "The Fisherman's Net" it takes the intervention of a magical power to catch the special fish desired by the princess. Therefore, magic supplements much of what is desired or unexplained in traditional societies. Similar to the element of magic, the themes of good and evil have a universal significance and yet they often appear to be slightly different in each culture. In the stories included in this collection the concept of good 
seems always to the fore. In repeated instances good begets favor while evil results in harm to both oneself and to others. The idea of goodness to all despite class or position is reinforced by the Afghan tradition of interdependence and cooperation and to some extent by religious teachings, Moreover, in the conflict of good and evil the supernatural force is most often on the side of the former. Thus, when an individual possess such attributes as basic intelligence, honor or obedience he frequently receives the help of a magic power. In the tale "The Garden of Genies" such things as knowledge, loyalty and love aid a princess in her search for her husband who has mysteriously disappeared. These virtues combined with perseverance win to her side the magical power of the genies who restore the prince, her husband, to life. Thus, it seems that "goodness" is a value exemplified in the Afghan folktale themes.

\section{Analysis of Additional Stories}

The remaining tales in the collection which were not discussed in the previous paragraphs are stories of amusement and the fables. The former such as "The Sparrow's Questions", "The White Goat" or "Why Bats Fly" seem to have no real cultural themes. Rather their primary purpose appears to be one of entertainment particularly for young children. The charm of the narrative which is sometimes bittersweet, the simplified subject matter and the easily identifiable characters are within the range of the preschool level. Moreover, the delight of repetition such as found in "The Sparrow's Questions" or the slight suspense which builds in "The White Goat" has great appeal and satisfying qualities for this age group. Thus, the simplified plots, the slow reiteration of dialogue, the suggestion of drama and the familiar set in a creative, but pleasant framework can form a delightful experience for the young child. 
The fables on the other hand belong to the universal tradition of moral tales. They are the short narratives whose characters being either animals or humans represent symbols of known behavior. Storytellers early recognized that the tales offered a fascinating way to give concrete form to abstract principles and to teach worldly wisdom in a practical way.

The fables included here are similar to those read in collections from India, Persia, Greece and the like. They reflect such principles as:"Don't count your chickens before they hatch" as shown in the tale "Building Castles in the Air"; "Minor disagreements may lead to unforeseen tragedy" from "The Nightingale and the Dog"; "It is better to be happy with what you have for to be exact in attempting equality may result in total loss" from "The Two Cats." Because of the universal significance of these tales no attempt will be made to analyze them. Rather they are presented as a part of the Afghan tradition reflecting as in other cultures the universal values to be learned couched in an entertaining form.

In the final analysis one finds certain cultural trends which are reflected in the themes and values of the stories. From the religious tradition there seem to be three major considerations. The first is the concept of fate or predestination which is unquestionably accepted and viewed as unchangeable. Examples of stories which support the idea are "The Princess and the Slave" and "The Wicked Daughter." Secondly, there is stressed the need for obedience to divine laws and order and for respect to the power of the supernatural as shown in "The Princess and the Slave" and "Baba Kharkash and the Magic Duck." In addition this obedience should extend to the sages and magicians who perhaps mirror the power of good. The opposite point of view, however, as seen in "The Magic Flower" indicates that when resources are used for evil or dishonest purposes, destruction will be the results. A third concept is that of material possessions. In the stories such as "The Old Woman" or "The 
Yellow Cow", worldly goods are of secondary importance, when compared to virtues of character which include kindness, friendship or honesty. There are also the values which are derived from tribal tradition. Included here is first the idea of promise which must be honored at any cost as suggested in the story "The Magic Flower". Second, cooperation and interdependence is necessary as each member of the group is expected to work towards a common goal as reflected in the tale of "The Palace of Diamonds." In addition self determination and pride in achievement also have value in an interdependent society. Domination by a particular individual or group is both feared and hated. Sometimes forces from the supernatural will provide additional impetus as shown in the tale of "The orphan" where individual drive coupled with magic provides for the happy resolution of the challenges at hand. Finally, loyalty is to be valued, the reality of which must be won through respect, not blind obedience. The example used here in "Baba Bilisti" indicates a loyalty expressed through love which enables the characters to overcome the obstacles and to achieve a successful conclusion. In the area of social relationships, certain patterns are evident which pertain to individual, family and group behavior and attitudes. On the individual level the example taken is that of the role women are expected to play in society. On one hand there is the trend which stems from the Islamic tradition and is reflected primarily in the rural agrarian communities. Here women as noted in "The Palace of Diamonds" are expected to assume a subordinate position obeying without question the decisions of their families or husbands. On the other hand there are the attitudes of the tribal system which permit women a greater share of responsibility and participation in the social group. This can be seen in "The Magic Ring" where the woman is actually the hero of the tale. 
In the family organization there are also certain values which each member is expected to collectively uphold. Among the most important of these is that of family honor through the preservation of the good name and reputation of the particular unit. The failure to meet this expectation whether it be real or imaginary can lead to unfortunate consequences as in "The Quince Fruit."

The association of families into larger groupings has created a hierarchy of social classes. Ancestry and to some extent wealth, reputation and position determine one's social standing in a highly organized traditional system. However, in such stories as "Baba Kharkash and the Egg of Happiness" or "The Yellow Cow" the theme of breaking through social barriers and thereby achieving higher social status is evident. The values emphasized here are individual honesty, effort, intelligence and prestige. These reinforced with the proper social recognition creates the possibility of an individual rising to a higher social position.

Finally, in the discussion of cultural themes in folktales certain elements are evident in the historical stories of "Fata and His Love" and "Sultan Mahmoud". In the former the emphasis is placed on the disgrace and eventual destruction of those who conduct themselves dishonorably in battle. In the latter the stress is on those qualities which a wise ruler should possess. Included are such things as justice, concern for the people's welfare and effort devoted to the creation of a viable state.

The themes of magic and good versus evil deeds are universal in nature. For example, magic has served as an explanation of cause and effect in nature as well as a means of extending man's limited world through fantasy and goodness and seems to have an appeal to mankind by its very nature. However, on occasion these concepts have additional significance in a cultural context. In Afghan folktales the origins of supernatural powers suggest a change which has occurred within the society. In "The Princess and the Slave" the sources of power are 
attributed to celestial bodies where as in "Baba Kharkash and the Magic Duck" the religious elements indicate a more sophisticated explanation of supernatural law which is probably the result of the Islamic influence in the country.

In addition magic supports efforts to achieve. In "The Fishermen's Net" a supernatural power helps to extend an individual's ability to cope with nature. Again in "The Garden of Genies" magic reinforces the achievement of the heroine. Here one also recognizes the idea that good will be rewarded while evil will be punished. In repeated instances the theme of goodness occurs often supported by a magic power, yet the values of good character, honesty, loyalty and the like must be present to reinforce this major concept.

Thus, the general cultural outlook of Afghanistan is identifiable to some extent in the folktale themes. The mode of life, the chief interests of the people and the values which they possess are mirrored in the stories along with the more universal themes. 